\title{
EL PAPEL DEL JUEZ EN UNA SOCIEDAD DEMOCRÁTICA ${ }^{1}$ THE ROLE OF THE JUDGE IN A DEMOCRATIC SOCIETY
}

\author{
LUIS LÓPEZ GUERRA*
}

Recibido: 08/11/2018

Aceptado: 21/11/2018

SUMARIO: I.- EL PRINCIPIO DEMOCRÁTICO COMO LEGITIMADOR DEL PODER. II.- MANIFESTACIONES DEL PRINCIPIO DEMOCRÁTICO: SUJECIÓN DEL JUEZ A LA LEY. III.- MANIFESTACIONES DEL PRINCIPIO DEMOCRÁTICO: GARANTÍA DE LOS DERECHOS FUNDAMENTALES. IV.- EL CONTENIDO CREADOR DE LA FUNCIÓN JUDICIAL. V.- EL PAPEL DE LOS DERECHOS FUNDAMENTALES EN LA APLICACIÓN E INTERPRETACIÓN DEL DERECHO POR EL JUEZ. VI.- CRITERIOS DE INTERPRETACIÓN DEL DERECHO DERIVADOS DE LOS DERECHOS FUNDAMENTALES. VII.- EL PAPEL DEL JUEZ EN UNA SOCIEDAD DEMOCRÁTICA COMO SUJETO A LA LEY Y COMO GARANTE DE LOS DERECHOS FUNDAMENTALES: LA “INTERPRETACIÓN CONFORME”. VIII.- PODER JUDICIAL Y CONTROL DE LAS LEYES. DIVERSIDAD DE VÍAS. IX.- BIBLIOGRAFÍA.

SUMMARY: I.- THE DEMOCRATIC PRINCIPLE AS LEGITIMATE OF POWER. II.DEMONSTRATION OF DEMOCRATIC PRINCIPLE: SUBJECTION OF THE JUDGE TO THE LAW. III.- DEMONSTRATION OF DEMOCRATIC PRINCIPLE: GUARANTEE OF FUNDAMENTAL RIGHTS. IV.- THE CREATING CONTENT OF THE JUDICIAL FUNCTION. V.- THE ROLE OF FUNDAMENTAL RIGHTS IN THE APPLICATION AND INTERPRETATION OF LAW BY THE JUDGE. VI.- CRITERIA FOR INTERPRETATION OF LAW FROM FUNDAMENTAL RIGHTS. VII.THE ROLE OF THE JUDGE IN A DEMOCRATIC SOCIETY AS SUBJECT TO THE LAW AND AS GUARANTOR OF FUNDAMENTAL RIGTHS: THE CONFORMING INTERPRETATION. VIII.JUDICIAL POWER AND CONTROL OF LAWS: DIVERSITY OF ROADS. IX.- BIBLIOGRAPHY.

Resumen: El principio democrático supone la sujeción del juez a la ley elaborado por la representación popular. Pero el juez ni puede limitarse a aplicar mecánicamente la ley, pues en muchos casos esta necesita una interpretación. Desde este punto de vista, el juez crea Derecho.

Esta creación es compatible con el principio democrático si la interpretación judicial se lleva a cabo en el marco de los principios y de los derechos fundamentales contenidos en la Constitución democrática y en los convenios internacionales sobre esos derechos ratificados por el Estado.

\footnotetext{
${ }^{1}$ El presenta trabajo reproduce, con alguna adición y bibliografía, la ponencia presentada por el autor en el Seminario Internacional "El Juez y el Estado de Derecho en las democracias contemporáneas" organizado por la Suprema Corte de Justicia de la Nación, y celebrado en la Ciudad de México el 11 de septiembre de 2018.

* Profesor en la Universidad Carlos III de Madrid.
}

https://dx.doi.org/10.17651/rej.n18.a5

Revista de Estudios Jurídicos nº 18/2018 (Segunda Época) ISNN 2340-5066. Universidad de Jaén (España)

Versión electrónica: rej.ujaen.es 
Palabras claves: democracia, poder judicial, interpretación judicial, convenios internacionales, derechos humanos.

\begin{abstract}
The democratic principle implies that judges are bound by the law established by the representants of the people. But judges do not just apply mecanichally the law, as legal mandates very often require interpretation. From this point of view, judges create law. This creation is compatible with the democratic principle if the judicial interpretation is performed within the framework of the principles and the fundamental rights contained in the democratic Comnstitution and in the international instruments on these rights ratified by the State.
\end{abstract}

Key words: democracy, judicial power, judicial intrepretation, intrenational conventions, human rights.

\title{
I.- EL PRINCIPIO DEMOCRÁTICO COMO LEGISLADOR DEL PODER
}

El principio democrático (esto es, que la justificación del sistema político reside en último término en la voluntad de los ciudadanos) constituye hoy, en forma general, el fundamento aceptado de la legitimidad de los poderes del Estado. Este principio encuentra desde luego expresión, también en forma general, en los documentos constitucionales, pero también, y como prueba de su común aceptación, en los instrumentos internacionales que rigen hoy las relaciones entre países: así, la Declaración Universal de Derechos Humanos de la Asamblea General de Naciones Unidas proclama en su artículo 21. 3 que "la voluntad del pueblo debe ser la base de la autoridad del gobierno”. En la misma línea, y recogiendo los elementos básicos de la democracia, el artículo 25 del Pacto Internacional de Derechos Civiles y Políticos establece que todos los ciudadanos gozarán de los derechos de participar en la dirección de los asuntos públicos directamente o por medio de representantes, así como de votar y ser elegido en elecciones libres y de atener acceso en condiciones de igualdad a las funciones públicas. En el nivel regional europeo, el Convenio Europeo de Derechos Humanos no sólo contiene menciones directas referentes a las exigencias de una sociedad democrática (así artículos 8, 9, 10 y 11) sino que en su Protocolo primero establece la obligación de los poderes públicos de celebrar elecciones libres que aseguren la expresión de la voluntad popular. En forma expresiva, esta dimensión "universal" de la democracia como forma de gobierno ha sido sustentada por la jurisprudencia del Tribunal Europeo de Derechos Humanos, al señalar que "la democracia (...) se muestra como el único modelo político contemplado por le convenio, y el único compatible con el mismo”2.

\footnotetext{
${ }^{2}$ United Communist Party of Turkey and others v. Turkey, (1998) Fundamento 45. Ver sobre este tema, WOJTYCZEK, K., "International and European Standards of State Organization” en MOTOC, I. et. al (Eds.), New Developments in Constitutional Law. Essays in Honour of Andras Sajo, Eleven International Publishing, The Hague, 2018, pp. 487-510, especialmente p. 492.
}

\section{Revista de Estudios Jurídicos nº 18/2018 (Segunda Época) ISNN-e 2340-5066. Universidad de Jaén (España) \\ Versión electrónica: rej.ujaen.es}


En todo caso, y como es evidente, de la justificación democrática del poder como principio general no se deriva que únicamente sea posible, a la luz de ese principio, una configuración específica de los poderes públicos: esa configuración dependerá de las circunstancias propias de cada país, reflejando su “identidad constitucional”, para emplear los términos del artículo 4 del Tratado de la Unión Europea, y se traducirá en la adopción de modelos tan distintos como el parlamentario o el presidencial (o incluso el gobierno de asamblea) y en el plano territorial, fórmulas unitarias, regionales o federales.

\section{II.- MANIFESTACIONES DEL PRINCIPIO DEMOCRÁTICO: SUJECIÓN DEL JUEZ A LA LEY.}

Así y todo, y partiendo tanto de las proclamaciones constitucionales como de los instrumentos de Derecho internacional es posible destacar algunos elementos del sistema político que en todo caso aparecen estrechamente vinculados al principio democrático. De estos elementos hay al menos dos que se proyectan directamente sobre la posición y funciones del juez, y cuya compaginación no ha dejado de dar lugar, aún hoy, a considerables dudas y polémicas tanto en el plano jurídico como en el práctico.

El primero de estos principios sería el imperio de la ley, y la sujeción a la misma del poder judicial. Sin duda, la existencia de un sistema democrático supone que la acción de los poderes públicos debe responder a la voluntad popular, voluntad que ordinariamente se expresa a través del poder legislativo, ejercido por asambleas seleccionadas mediante elecciones libres. La ley viene pues a legitimar, no sólo la actuación del juez, en cuanto ejecutor de sus mandatos, sino la misma existencia y composición de los órganos jurisdiccionales, por cuanto deberán estar constituidos de acuerdo con la ley. La sujeción a la ley implica, como es bien sabido, una serie de características necesarias para que pueda calificarse como tal a un tribunal, esencialmente la imparcialidad y su inmediato correlato, la independencia. El Tribunal de Estrasburgo ha podido así resumir en Belilos contra Suiza, esas características esenciales:

Según la jurisprudencia del Tribunal, un «tribunal» se caracteriza, en el sentido de fondo del término, por su función judicial: resolver, conforme a las reglas del Derecho y después de un procedimiento reglado, cualquier cuestión que dependa de su competencia (véase la reciente Sentencia en el caso H. contra Bélgica, de 30 de noviembre de 1987, serie A, núm. 127, pág. 34, apartado 50). Ha de reunir también una serie de requisitos -independencia, especialmente en relación al Poder Ejecutivo, imparcialidad, inamovilidad, garantías de procedimientovarios de los cuales aparecen en el propio texto del artículo 6.1 (véase, entre otras, la Sentencia en el caso Le Compte, Van Leuven y De Meyere, de 23 de junio de 1981, serie A, núm. 43, pág. 24, apartado 55).3

\footnotetext{
${ }^{3}$ Belilos contra Suiza (1998) pár. 64. Ver al respecto WOJTYCZEK, K. cit. p. 501. 
La reducción de la legitimidad del juez a la legitimidad de la ley no es, desde luego, un descubrimiento reciente; puede encontrarse ya en la obra de Montesquieu, al definir al juez como el "instrumento que pronuncia las palabras de la ley" 4 (y sobre esto se harán algunas reflexiones más abajo). El desarrollo del constitucionalismo democrático ha venido a convertir esa legitimidad en legitimidad democrática, al identificar la ley con la voluntad popular. La legitimidad del juez resulta una legitimidad de ejercicio. El juez, en ejercicio de su "terrible poder" para utilizar la expresión de Montesquieu5, no aplica más voluntad que la voluntad de la ley; no aplica la voluntad de otros sujetos, ni siquiera la suya propia.

El juez se inserta dentro de la legitimidad democrática de los poderes del estado en cuanto se convierte en mecanismo de aplicación, en casos concretos, de la voluntad del pueblo, manifestada en forma general en la ley. Tal es el sentido de la expresión del artículo 117 de la Constitución española "la justicia emana del pueblo". Tal es el fundamento de la exigencia de independencia e imparcialidad del juez. No puede someterse a los mandatos e influencias e otros (independencia) ni puede por otro lado, decidir en virtud de preferencias o intereses personales (imparcialidad). 6

\section{III.- MANIFESTACIONES DEL PRINCIPIO DEMOCRÁTICO: GARANTÍA DE LOS DERECHOS FUNDAMENTALES.}

Junto a este elemento, si se quiere “formal” del sistema democrático, un segundo elemento, de innegable trascendencia para la función del juez, aparece como esencial en ese sistema: la afirmación de los derechos fundamentales de la persona. La vinculación entre estos dos aspectos de la democracia aparece con frecuencia expresamente reflejada en instrumentos nacionales e internacionales7; en términos de Ferrajoli, los derechos fundamentales se configuran como la "dimensión sustantiva de la democracia"8

Esta posición de los derechos fundamentales resulta de diversas causas, de forma que democracia y derechos de la persona parecen como conceptos indisociables. Por un lado, por razones estrictamente instrumentales; sería impensable un sistema democrático, basado en la voluntad del pueblo expresada en elecciones libres, sin la

\footnotetext{
${ }^{4}$ MONTESQUIEU, El espíritu de las leyes, Libro XI, Capítulo VI, “De la constitución de Inglaterra”, p. 227 y ss.: "Los jueces de la nación no son, como hemos dicho, más que el instrumento que pronuncia las palabras de la ley, seres inanimados que no pueden moderar ni la fuerza ni el rigor de las leyes".

${ }^{5}$ MONTESQUIEU, El espíritu de las leyes, ibídem, "De esta manera, el poder de juzgar, tan terrible para los hombres, se hace invisible y nulo, al no estar ligado a determinado estado o profesión".

${ }^{6}$ Ver sobre este tema, LÓPEZ GUERRA, L., El Poder Judicial en el Estado Constitucional, Lima, Palestra, 2001, p. 23.

7 Por ejemplo, en el Preámbulo del Convenio Europeo de Derechos Humanos: "Reafirmando su profunda adhesión a estas libertades fundamentales que constituyen las bases mismas de la justicia y de la paz en el mundo, y cuyo mantenimiento reposa esencialmente, de una parte, en un régimen político verdaderamente democrático, y, de otra, en una concepción y un respeto comunes de los derechos humanos de los cuales dependen".

${ }^{8}$ FERRAJOLI, L., Derecho y razón. Teoría del garantismo penal, Trotta, Madrid, 2009, p. 883. Cf. ANDRÉS IBAÑEZ, P. "La independencia judicial y los derechos del juez", en SAIZ ARNAIZ, A. (Dir.) Los derechos fundamentales de los jueces, Marcial Pons, Madrid, 2012, pp. 45-64, 48.
}

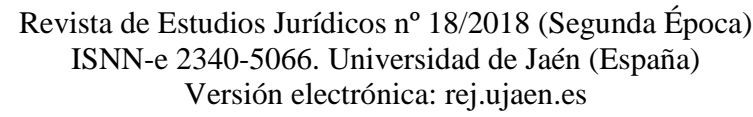


previa garantía de un conjunto de derechos que asegurasen la libre expresión de las preferencias de los ciudadanos.

Pero, además, la garantía de esos derechos cumple una función aún más decisiva; la de representar la misma base de la Constitución, en cuanto expresión de unos valores comunes fundamento de la organización política de la comunidad. Valores comunes que hoy tienen una extensión supranacional, en cuanto consagrados como fundamento de la misma comunidad internacional, bien con alcance general (como en la declaración Universal de Derechos Humanos) bien con alcance regional (como en las Conexiones Europea y Americana de Derechos Humanos). Los derechos de la persona se configuran así hoy como elemento legitimador de la Constitución democrática.

La función del juez en una sociedad democrática se ve así delimitada, formalmente, por la sujeción a la ley como expresión de la voluntad popular, y sustantivamente por el respeto a los derechos fundamentales establecidos tanto en el nivel nacional como en el internacional. Y esta doble delimitación supone una considerable complejidad, en la práctica, en el desarrollo de las funciones judiciales. Pues cabe, al respecto, alguna consideración en cuanto al contenido, hoy de la función judicial.

\section{IV.- EL CONTENIDO CREADOR DE LA FUNCIÓN JUDICIAL.}

Se ha hecho referencia, más arriba, a la definición de Montesquieu del juez como el "instrumento que pronuncia las palabras de la ley". Pero no es ninguna novedad constatar que se trata de una expresión por lo menos desorientadora en lo que se refiere a la función actual del juez en un sistema democrático. Pues el juez, al aplicar el Derecho (es decir, al llevar a cabo una aplicación, no sólo de una norma aislada, sino, como es necesario, del ordenamiento jurídico) realiza una labor forzosamente creadora del Derecho. Desde luego, no cabe dudar de que el juez, al resolver un caso concreto, crea Derecho, en cuanto lleva a cabo una declaración del Derecho en un pleito inter partes, dando lugar a una nueva situación jurídica singular. Pero, desde una perspectiva general y atendiendo, no sólo a la actuación de un juez particular, sino a la del poder judicial en su conjunto, no cabe dudar tampoco de que el juez crea Derecho, en el sentido de establecer pautas de comportamiento vinculantes jurídicamente frente a terceros, más allá de las partes en el caso. Y ello, desde luego, sin que tal creación suponga un apartamiento del principio democrático de sujeción a la ley.

La necesidad de una labor creadora de Derecho por parte del juez deriva de la misma naturaleza del Derecho en una sociedad organizada de acuerdo con un modelo constitucional e integrada en la sociedad internacional. Pueden apuntarse una serie de causas que obligan a esta creación judicial del Derecho. Por una parte, y desde luego, los mismos defectos e imperfecciones del sistema legal: en palabras de un juez del Tribunal Supremo español, 


\begin{abstract}
"Como es sabido, las imperfecciones del ordenamiento jurídico- sus insuficiencias, ambigüedades, contradicciones, o simplemente su extraordinaria complejidad- hacen que la tarea de juzgar sea particularmente difícil, no ya porque muy a menudo sea complicado establecer los hechos y comprender los planteamientos de las partes sino porque con gran frecuencia es extraordinariamente arduo identificar la norma aplicable. De ahí que en muchas ocasiones, el juez, más que localizarla, deba construirla con los materiales que le ofrece el ordenamiento jurídico9.
\end{abstract}

Esta situación se debe a razones bien conocidas. Por una parte, la imposibilidad de que el legislador pueda prever absolutamente todas las particularidades de los supuestos en que una norma deba aplicarse, particularidades que sin embargo el juez debe tener en cuenta. Pero además, y muy frecuentemente, la norma a aplicar no está contenida en una sola disposición legal, sino que es resultado de aplicación conjunta de diversas reglas, tanto de origen nacional como internacional, que el juez debe compaginar para llegar a un resultado acorde con el ordenamiento en su conjunto; compaginación que supone una tarea de integración de normas y que fuerza a ir más la de su significado literal, consideradas aisladamente. Tarea que se ve además complicada por la frecuente presencia de lagunas legales, y por la utilización por el legislador de términos en ocasiones lo suficientemente vagos o abstractos como para necesitar una concreción que sólo el juez puede llevar a cabo.

Ciertamente, la tarea creativa del juez se produce en un caso concreto. Pero las exigencias de la seguridad jurídica, y el principio de igualdad llevan a que los criterios empleados por los diversos tribunales no puedan ser imprevisibles o contradictorios. Como es bien sabido, es la tarea de los tribunales superiores llevar a cabo la unificación de la doctrina a través del principio stare decisis, entendido tanto en el sentido de la vinculación de cada tribunal a la doctrina sentada anteriormente en casos similares, como en la sujeción de los tribunales inferiores a la doctrina establecida por los órganos jurisdiccionales supremos, en virtud de la fuerza de res interpretata10.

Desde esta perspectiva, el papel del juez (tanto del juez individual, al resolver cada caso, como del poder judicial como colectivo, al establecer líneas jurisprudenciales) se enfrenta con la ardua tarea de completar la obra del legislador, deduciendo del ordenamiento normas que pueden no resultar inmediatamente evidentes a partir de la normativa legal. Se trata de una función extremadamente compleja y delicada, por cuanto la seguridad jurídica exige que los criterios para la interpretación y adecuación del ordenamiento no sean resultado del mero voluntarismo o preferencia coyuntural de

\footnotetext{
9 MURILlO DE LA CUEVA, P., “La independencia judicial y la ley” en BANDRES SÁNCHEZ CRUZAT J., y CONTRERAS CASADO, M. (Dirs.) Parlamento y Poder Judicial, Consejo General del Poder Judicial, Madrid, 2007, pp. 73-108, 109.

10 Me remito en este punto a mi trabajo "El Tribunal Constitucional y el principio stare decisis", publicado en El Tribunal Constitucional (Vol. II), Instituto de Estudios Fiscales, Madrid, 1981, pp. 14331456.
}

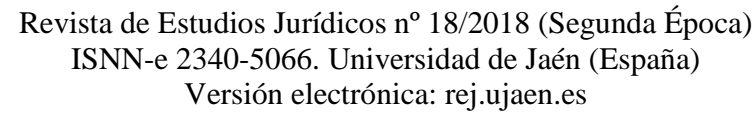


los órganos judiciales, sino que estén justificados en cuanto respondan a los principios básicos del ordenamiento y sean compatibles con una sociedad democrática.

\section{V.- EL PAPEL DE LOS DERECHOS FUNDAMENTALES EN LA APLICACIÓN E INTERPRETACIÓN DEL DERECHO POR EL JUEZ.}

Es en este punto donde los derechos fundamentales (o, cuando se habla en el ámbito internacional, los derechos humanos) cumplen un papel decisivo en cuanto elemento esencial de interpretación de las normas jurídicas. En efecto, en el constitucionalismo democrático actual puede verificarse que los derechos fundamentales adoptan un doble carácter. Por un lado, aparecen como definidores de un ámbito de libertad individual, que supone unas concretas facultades de la persona (física o jurídica) que le legitiman para una serie de pretensiones, tanto materiales como procesales, frente a los poderes públicos y (aunque este aspecto merecería una más amplia digresión) sujetos particulares. Pero, por otro lado, aparecen como elementos objetivos del ordenamiento jurídico, como mandatos que reflejan un orden de valores que se proyecta sobre todo el ordenamiento.

Valga decir que ello no supone una invocación de un pretendido "Derecho natural" que contendría una enumeración de derechos válidos independientemente de toda normativa o reconocimiento positivo. El carácter objetivo de los derechos fundamentales, por el contrario, es reconducible sin dificultad a las mismas peculiaridades del constitucionalismo democrático y de la moderna sociedad internacional. Es comúnmente admitido que dentro de las normas jurídicas cabe apreciar la presencia tanto de reglas que representan mandatos específicos de cumplimiento forzoso y delimitado, como de principios que tienen una más amplia dimensión y que representan mandatos de optimización de determinadas situaciones y relaciones, de acuerdo con unos valores que se establecen como base común de la convivencia11. Respecto de las normas que establecen derechos fundamentales, este doble carácter se manifiesta en diversas formas. Por un lado, por cuanto los derechos fundamentales representan elementos esenciales del orden político; piénsese por ejemplo en la función del derecho a la libertad de expresión como derecho individual y como garantía del sistema democrático. Por otro, por cuanto reflejan unos principios éticos que se estiman como base para la convivencia. Y todo ello, no sobre la base de consideraciones meramente morales, sino a la vista de los efectos del reconocimiento de los derechos en los textos constitucionales y en los instrumentos supranacionales. Desde luego, como efecto del reconocimiento constitucional.12 Pues, como ha podido decirse, los derechos

\footnotetext{
${ }^{11}$ No es éste el lugar para exponer la amplia bibliografía referente a los conceptos de reglas, principios y procedimientos como elementos del ordenamiento, reflejados en el diálogo entre autores como DWORKIN, ALEXY o McCORMICK. Una discusión general puede encontrarse en los ensayos contenidos en ORTEGA GARCIA, R., (Coord.) Interpretación y argumentación jurídica en el Estado Constitucional, Tirant lo Blanch, México, 2015. En lo que se refiere al doble carácter de los derechos fundamentales, baste remitirse aquí a BASTIDA FREIJEDO, F., et. al. Teoría General de los Derechos Fundamentales en la Constitución española de 1978, Tecnos, Madrid, 2004, pp. 47 y ss.

12 Por ejemplo, en palabras del Tribunal Constitucional español, (STC 9\&181, FJ 3) la Constitución ostenta un carácter de "norma cualitativamente distinta de las demás por cuanto incorpora el sistema de valores esenciales que ha constituir el orden de convivencia política y de informar tdo el ordenamiento 
fundamentales reconocidos en la Constitución no son sino la traducción jurídica de los elementos básicos del sustrato ético de la sociedad.13 Y, en lo que atañe a los derechos reconocidos en instrumentos internacionales, su carácter informador del ordenamiento es consecuencia de su integración en el mismo como Derecho vigente en virtud del sistema de fuentes propio, y la asunción del carácter de “derechos fundamentales” de los derechos en esos instrumentos reconocidos. Valga aquí recordar a este respecto el mandato del artículo 10.2 de la Constitución española:

"Las normas relativas a los derechos fundamentales y a las libertades que la Constitución reconoce se interpretarán de conformidad con la Declaración Universal de Derechos Humanos y los tratados y acuerdos internacionales sobre las mismas materias ratificados por España”.

\section{VI.- CRITERIOS DE INTERPRETACIÓN DEL DERECHO DERIVADOS DE LOS DERECHOS FUNDAMENTALES}

El papel de los Convenios Internacionales sobre derechos humanos (y de los órganos jurisdiccionales que los aplican) resulta especialmente relevante a la hora de proporcionar al juez, en forma general, criterios para la interpretación y aplicación del ordenamiento a la luz de esos derechos (llámense derechos fundamentales o derechos humanos, según el contexto). En efecto, si bien cada sistema constitucional nacional presenta sus propia características y su propia identidad (y por ello, resulta más difícil establecer pautas comunes de interpretación a partir de mandatos constitucionales, aun cuando esta sea una tarea frecuentemente desarrollada en el ámbito académico) la existencia de sistemas regionales de protección de derechos humanos en que una serie de Estados se comprometen a reconocer y respetar una lista de derechos, y a someterse a las resoluciones de un órgano jurisdiccional internacional, convierte a los criterios adoptados por estos tribunales en líneas interpretativas aplicables en contextos muy diferentes.

Pues las resoluciones de los tribunales internacionales de derechos humanos (y señaladamente, los dos tribunales de referencia en este campo, el Tribunal Europeo y la Corte Interamericana de Derechos Humanos) no solamente resuelven casos concretos y fijan el contenido de los derechos reconocidos en los respectivos Convenios, sino que al tiempo llevan a cabo afirmaciones de tipo general respecto de la forma en que esos derechos han de interpretarse, afirmaciones que resultan por tanto ( y ello se confirma en la práctica) guías para la aplicación por los tribunales domésticos de los derechos convencionales y, en forma conexa ( por cuanto, evidentemente, no existe una línea radical de separación entre derechos convencionales y derechos fundamentales constitucionales), de los derechos fundamentales en cada ordenamiento. Valga señalar desde un principio que los criterios interpretativos suministrados por ambas cortes,

jurídico”. Cfr. REVENGA SÁNCHEZ, M., Derechos Fundamentales y constitucionalismo, Editorial Porrúa, México, 2014, p. 117.

13 PÉREZ TREMPS, P., “Los derechos fundamentales. Teoría general” en PÉREZ TREMPS, P., (Coord.)

Los derechos fundamentales, Corporación Editora Nacional, Quito, 2004, p.9.

Revista de Estudios Jurídicos nº 18/2018 (Segunda Época)

ISNN-e 2340-5066. Universidad de Jaén (España)

Versión electrónica: rej.ujaen.es 
europea y americana, presentan, como no podía ser de otra forma, considerables similitudes, de manera que podría hablarse de líneas interpretativas comunes.14

\section{El carácter efectivo de los derechos como criterio interpretativo}

Uno de esos principios interpretativos comunes ha sido el referente a que, a la hora de interpretar y aplicar el Derecho, debe tenerse en cuenta la naturaleza de la protección, efectiva y no meramente formal, que debía prestarse a los derechos que ambos sistemas reconocían. Este principio fue expresado por el Tribunal de Estrasburgo en su sentencia en el caso Airey contra Irlanda el año 1979:”El Convenio pretende garantizar derechos que no sean meramente teóricos o ilusorios, sino que sean prácticos y efectivos” (§24).

Esta pretensión de efectividad se traduce en una interpretación que pone el acento en el contenido del derecho desde una perspectiva teleológica: el texto del Convenio ha de interpretarse de acuerdo con el fin que se propone, despejando interpretaciones estrictamente literalistas. A este respecto, los fines del Convenio aparecen expresamente establecidos en su Preámbulo, como elemento a tener en cuenta para su interpretación.15 Pero además, el Tribunal ha tenido en cuenta el contexto en que el Convenio aparece, y sus finalidades últimas, esto es, el mantenimiento de Estados democráticos de Derecho: en palabras del Tribunal, "cualquier interpretación de los derechos y libertades garantizados ha de ser consistente con el espíritu general del Convenio,, como instrumento diseñado para mantener y promover los valores e ideales de una sociedad democrática”16.

No es difícil encontrar afirmaciones similares en la jurisprudencia de la Corte de San José, con referencias al principio de effet utile de los mandatos de la Convención, y a la obligación de las autoridades de los Estados miembros de proporcionar, a la hora de interpretar y aplicar el Derecho, una protección efectiva de los derechos de la Convención. Como pudo señalar el juez Sergio García Ramírez en su voto concurrente a Comunidad Mayagna, (2001), el objeto y fin de la Convención se concentran en el reconocimiento de los derechos de las personas y en la previsión de instrumentos jurídicos a este fin.

En esta línea, por ejemplo, en López Lone y otros v. Honduras (2015) la Corte estableció que "Como este Tribunal ha señalado en otras oportunidades, las disposiciones de Derecho interno que se adopten para tales fines han de ser efectivas (principio del effet utile), lo que significa que el Estado tiene la obligación de consagrar y adoptar en su ordenamiento jurídico interno todas las medidas necesarias para que lo

\footnotetext{
${ }^{14}$ Me he referido a estas líneas comunes en mi artículo "La evolución de los sistemas de protección internacional de los derechos humanos”, publicado en Parlamento y Constitución. Anuario, 18 (2017), pp. 81-102, cuyas consideraciones reproduzco en algunas de las líneas que siguen.

${ }^{15}$ Ver al respecto MATSCHER, F., "Les contraints de l'interprétation juridictionnelle. Les méthodes d'interprétation de la Convention Européenne » en SUDRE, F., (Ed.), L’interprétation de la Convention européenne des droits de l'homme, Bruylant, Bruselas, 1998, pp.15-40.

${ }^{16}$ Soering c. Reino Unido, de 7 de julio de 1989, §87. 
establecido en la Convención sea realmente cumplido y puesto en práctica” (par. 214). Afirmaciones similares pueden encontrarse, por ejemplo, en Personas Dominicanas v. República Dominicana (2014, par. 271) o en Gelman v. Uruguay. Supervisión del cumplimiento (2013, par.63). El principio del effet utile respecto de los mandatos de la Convención se ha extendido también respecto de los remedios internos establecidos en los Estados miembros para reparar los daños causados por vulneraciones de derechos de la Convención (Velásquez Rodríguez v. Honduras, 1988, par. 66: Brewer Carias v. Venezuela, 2014, par. 87).

\section{Los Convenios internacionales como "instrumentos vivos"}

Habida cuenta de esta perspectiva, y como consecuencia lógica, ambas cortes han recalcado que, frente a una interpretación que pudiera llamarse "originalista" de ambos Convenios, éstos deben entenderse como instrumentos de protección de derechos también en el contexto de circunstancias cambiantes o imprevistas respecto de la existentes en el momento de su aprobación; ambos Convenios serían instrumentos vivos, que aspiran a mantener su vigencia y efectividad a través de cambios sociales de todo tipo.17 En palabras del juez del Tribunal de Estrasburgo Franz Matscher, "los conceptos de los que se sirve el Convenio deben entenderse en el sentido en que los comprenden las sociedades democráticas actuales, y no en el sentido que los conceptos tenían hace cuarenta años, cuando se elaboró el Convenio"18. Esto significa que, por un lado, el Tribunal de Estrasburgo considera que la interpretación de los derechos del Convenio debe llevarse a cabo en forma evolutiva, en el sentido de proporcionar una protección a los derechos allí reconocidos frente a amenazas y peligros derivados de nuevas situaciones, no previstas o imprevisibles para los autores del mismo.19

Pero, además, la interpretación del Convenio como un "instrumento vivo" se ha traducido en que el ocasiones el Tribunal de Estrasburgo ha venido a alterar su jurisprudencia en cuanto a la determinación del contenido de un derecho, teniendo en cuenta la evolución de las condiciones existentes en el contexto europeo, y el desarrollo de un consenso o standard consolidado al respecto en el ámbito de los países miembros. Ello puede percibirse en supuestos como la inclusión dentro de los derechos garantizados por el artículo 9 del Convenio de la objeción de conciencia al servicio militar (STEDH Bayatyan c. Armenia, de 7 de julio de 2011), o la apreciación de la importancia de un consenso europeo respecto del alcance del principio de irretroactividad de las normas penales (STEDH Scoppola c. Italia (2), de 17 de septiembre de 2009.

\footnotetext{
${ }^{17}$ SSTEDH Tyrer c. Reino Unido, de 25 de abril de 1978; Marckx c. Bélgica, de 13 de junio de 1979.

${ }^{18}$ MATSCHER, cit. p. 23.

19 Una muestra de estos supuestos de actuación del Tribunal interpretando el Convenio como un instrumento vivo frente a nuevas amenazas a los derechos humanos pudiera ser la representada por aquellos casos en que se ha ampliado el alcance del artículo 8, relativo al derecho a la vida privada y familiar y a la inviolabilidad del domicilio y la correspondencia. La sentencia en el caso López Ostra c. España (1994) vino a extender la protección de la Convención a los supuestos de invasión del domicilio por agentes nocivos y molestos, como los malos olores, dando lugar así, en forma refleja, a un derecho al "medio ambiente domiciliario"; en esta misma línea, las sentencias en los casos Gómez Moreno contra España (2004) y Martínez Martínez c. España (2011) incluyeron a los ruidos entre esos agentes nocivos.
}

$$
\begin{gathered}
\text { Revista de Estudios Jurídicos no 18/2018 (Segunda Época) } \\
\text { ISNN-e 2340-5066. Universidad de Jaén (España) } \\
\text { Versión electrónica: rej.ujaen.es }
\end{gathered}
$$


Esta línea argumental ha sido también adoptada en forma continua por la Corte de San José. Por ejemplo, y dando múltiples referencias, en Huapaya v. Perú (2015) afirmó que "la Corte ha señalado en otras oportunidades que los tratados de derechos humanos son instrumentos vivos cuya interpretación tiene que acompañar la evolución de los tiempos y las condiciones de vida actuales”. Y anteriormente, en Artavia Murillo v. Costa Rica (2012), manifestó que "tal interpretación evolutiva es consecuente con las reglas generales con las reglas de interpretación establecidas en el artículo 29 de la Convención Americana, así como en el Convenio de Viena sobre el Derecho de los Tratados”. Valga señalar también, como exponentes de esta posición, los votos separados del juez Vio Grossi en Galindo Cárdenas y otro v. Perú (2015) y Comunidad campesina de Santa Bárbara v. Perú (2015).

\section{La apreciación de las “obligaciones positivas” de los Estados}

Consecuencia también del carácter objetivo de los derechos fundamentales, a la hora de interpretar y aplicar el Derecho, es que de tales derechos derivan, no solamente límites a la actuación de los poderes públicos, sino también obligaciones de actuar de estos poderes20. Resultado de este enfoque interpretativo, ha sido la introducción por ambas cortes en su jurisprudencia del concepto de obligaciones positivas del Estado, derivadas del reconocimiento de derechos por los respectivos Convenios: esto es, que el respeto de esos derechos implica no solamente que las autoridades públicas deben abstenerse de actuaciones que interfieran indebidamente en su ejercicio por las personas bajo su jurisdicción, sino también, y adicionalmente, que esas autoridades tienen la obligación de proveer los medios necesarios para prevenir su vulneración, así como para la defensa efectiva de los mismos.

Por lo que se refiere al Tribunal de Estrasburgo, un ejemplo de reconocimiento de tales obligaciones positivas sería la jurisprudencia relativa a la protección de los derechos a la vida (artículo $2 \mathrm{CEDH}$ ) y a la integridad física frente a tratos inhumanos o degradantes (artículo $3 \mathrm{CEDH}$ ). En la jurisprudencia del Tribunal, la protección de estos derechos no se ciñe únicamente a lo referente a la interdicción de su violación material por las autoridades estatales. A partir de la sentencia Mac Cann c. Reino Unido21 el Tribunal ha venido a mantener que el derecho a la vida supone, no sólo la interdicción de atentados materiales contra este derecho, sino también la obligación de las autoridades (incluyendo las judiciales) de, en el supuesto de infracciones en este aspecto, llevar a cabo todas las investigaciones necesarias, con la intervención de las víctimas de la aducida vulneración, para determinar y explicar adecuadamente las circunstancias del caso, los culpables y las posibles reparaciones.

\footnotetext{
${ }^{20}$ Valga señalar en este aspecto, y respecto de la jurisprudencia del Tribunal Constitucional español, la sentencia 53/1985, reconociendo las "obligaciones positivas" derivadas de los derechos fundamentales. Ver sobre esta cuestión ESCOBAR, G., Introducción a la teoría jurídica de los derechos humanos, Universidad de Alcalá, Madrid, 2004, p. 48.

${ }^{21}$ STEDH de 27 de septiembre de1995.
}

Revista de Estudios Jurídicos no 18/2018 (Segunda Época) ISNN-e 2340-5066. Universidad de Jaén (España)

Versión electrónica: rej.ujaen.es 
Respecto de la Corte de San José, a partir de Velásquez Rodríguez, ha reiterado (por ejemplo en Gomes Lund y otro contra Brasil, 2011) que todos los órganos (de nuevo, incluyendo los tribunales) de los sistemas nacionales de derechos humanos tienen la obligación de investigar las violaciones graves de los mismos22. En este aspecto, pues, la jurisprudencia de ambas cortes sigue también caminos coincidentes.

\section{VII.- EL PAPEL DEL JUEZ EN UNA SOCIEDAD DEMOCRÁTICA COMO SUJETO A LA LEY Y COMO GARANTE DE LOS DERECHOS FUNDAMENTALES: LA “INTERPRETACIÓN CONFORME”}

Se muestra así como función destacada del juez en una sociedad democrática compaginar dos elementos básicos de la constitución; por un lado la sujeción a la ley como expresión de la voluntad popular; por otro, garantizar el respeto a los derechos fundamentales (recogidos directamente en la Constitución, o declarados en Convenios internacionales) como base de la convivencia. Ello supone ( dada la estructura de los derechos fundamentales a la vez como reglas y como principios, y la textura en ocasiones abierta de los mandatos legales) una tarea de adaptación y adecuación entre estos dos elementos, en ocasiones de forma evolutiva, dando lugar a lo que ha podido denominarse el Derecho dúctil,23 de forma que la compatibilidad entre derechos y ley se manifieste, tanto en los casos individuales como en la jurisprudencia de los Tribunales, sin vulneración del principio de seguridad jurídica.

Ello supone una labor de interpretación continua del Derecho por parte del conjunto del poder judicial, bajo la dirección última de los órganos jurisdiccionales superiores. Teniendo en cuenta el carácter de norma superior de la Constitución y la fuerza vinculante de los Convenios internacionales sobre derechos humanos, esta tarea aparece como función continua y ordinaria de los Tribunales.

Ahora bien, si en la mayoría de los casos la integración de ley y derechos no presentará excesivas dificultades, no cabe excluir que estas aparezcan en supuestos en que se den desajustes entre ambos elementos, en el sentido de que pueda producirse una falta de correspondencia entre el sentido inmediato de la literalidad de la ley y el contenido del derecho fundamental, como deriva de la Constitución o de un Convenio internacional, o de la correspondiente jurisprudencia en alguno de esos niveles. En estos casos, el papel del juez cobra una indudable relevancia, en cuanto encargado de velar por el mantenimiento del ordenamiento respetando tanto el principio democrático de la supremacía de la ley como la garantía, constitucional o internacional de los derechos fundamentales, a pesar de la (aparente) falta de correspondencia entre ley y derechos.

La doctrina académica y la práctica jurisdiccional han subrayado la importancia del papel de los Tribunales en estos supuestos en una labor de ajuste por medios interpretativos, singularmente mediante la técnica conocida como "interpretación

\footnotetext{
${ }^{22}$ Cf. BURGOGUE LARSEN, L. y MONTOYA CÉSPEDES, N., "El diálogo judicial entre el TEDH y la CIDH” en LÓPEZ GUERRA, L. y SAIZ ARNAIZ, A. (Dirs.) Los sistemas interamericano y europeo de protección de los derechos humanos, Palestra, Lima, 2015, pp. 348-349.

${ }^{23}$ ZAGREBELSKY, G. El Derecho dúctil, Trotta, Madrid, 1995.
}
Revista de Estudios Jurídicos nº 18/2018 (Segunda Época) ISNN-e 2340-5066. Universidad de Jaén (España)
Versión electrónica: rej.ujaen.es


conforme" consistente en atribuir, de los diversos significados posibles de la norma legal, aquel que resulte conforme (o al menos compatible) con las disposiciones constitucionales o convencionales24. Esta técnica deriva de lo que podría denominarse “deferencia hacia el legislador"; en el supuesto de la presencia de diversos sentidos posibles de una disposición, cabe suponer que el legislador pretendía establecer aquel que estuviera en consonancia con los derechos humanos, y no en su contra. Y ello incluso si esa interpretación supone un cierto esfuerzo en cuanto a la literalidad del texto legal, habida cuenta que éste tiene que leerse a la luz del conjunto del ordenamiento, y no de forma aislada. Valga señalar, como ya se apuntó más arriba, que el punto de referencia para llevar a cabo esta interpretación conforme lo constituyen, no sólo las disposiciones establecidas en los textos constitucionales o convencionales, sino también la jurisprudencia de los altos tribunales encargada de su interpretación. En relación con este aspecto, valga recordar que el artículo 8 de la Ley Orgánica del Poder Judicial española establece que en relación los derechos fundamentales,"se reconocerán en todo caso de conformidad con su contenido constitucionalmente declarado".

Y en cuanto al valor de la jurisprudencia internacional (en el caso, del Tribunal Europeo de Derechos Humanos) el mismo Tribunal Constitucional español ha podido establecer progresivamente, que la jurisprudencia de Estrasburgo representa "un medio de interpretación impuesto por el artículo 10.2 de la Constitución” (STC 114/1989, FJ 3). Y el mismo Tribunal ha destacado "la conveniencia e incluso obligatoriedad" de tener en cuenta la jurisprudencia del TEDH (STC 341/93) y ha admitido que es el Tribunal de Estrasburgo a quien corresponde" concretar el contenido de los derechos declarados en el Convenio" (STC 91/2000).

\section{VIII.- PODER JUDICIAL Y CONTROL DE LAS LEYES. DIVERSIDAD DE VÍAS}

Una cuestión más grave se plantea cuando tal interpretación conforme no se muestra como inmediatamente posible, y en cualquier caso el juez debe adoptar una resolución decidiendo el litigio. Desde luego, una primera posibilidad es la de que el juez efectúe una consulta respecto del contenido del derecho en cuestión, caso de dudas al respecto, y para verificar la conformidad con el mismo de la norma a aplicar. Así, debe indicarse a este respecto que en agosto de 2018 ha entrado en vigor el protocolo 16 al Convenio Europeo de Derechos Humanos, que prevé que:

"Los órganos jurisdiccionales de mayor rango de una Alta Parte Contratante, de acuerdo con lo especificado en el artículo 10, podrán solicitar al Tribunal que emita opiniones consultivas sobre cuestiones de principio relativas a la interpretación o a la aplicación de los derechos y libertades definidos en el Convenio o sus protocolos”.

\footnotetext{
24 SAIZ ARNAIZ, A., “Capítulo 9: la interpretación de conformidad y su dimensión práctica” en LÓPEZ GUERRA, L. y SAIZ ARNAIZ, A. (Dirs.), Los sistemas interamericano y europeo de protección de los derechos humanos. Una introducción desde le perspectiva del diálogo entre tribunales. Lima, Palestra, 2015, pp. 279-328.
}

Revista de Estudios Jurídicos nº 18/2018 (Segunda Época) ISNN-e 2340-5066. Universidad de Jaén (España)

Versión electrónica: rej.ujaen.es 
Y una disposición similar ( de hecho, fuente de inspiración parcial para el protocolo 16) es la contenida en el artículo 267 del Tratado de Funcionamiento de la Unión Europea, en cuanto prevé la formulación de cuestiones prejudiciales al Tribunal de Justicia de la Unión, cuestiones que podrán referirse a los derechos contenidos en la Carta de Derechos Fundamentales de la Unión; si bien, y a diferencia del caso del Protocolo 16 al Convenio, no se trata, como es bien sabido, de opiniones "consultivas”...

Con o sin la posibilidad de formular consultas previas de este tipo, no cabe excluir que corresponda al juez la verificación final de la incompatibilidad entre una norma legal y un derecho garantizado constitucional o convencionalmente. Y la posición del juez en estos supuestos límites se encuentra forzosamente determinada por las previsiones al respecto de su ordenamiento. Las vías de acción que se le ofrecen, en contextos distintos, varían considerablemente.

En un continuum de posibilidades, de la más moderada a la más radical, podría señalarse, de un lado la posibilidad de que el juez, aún vinculado a la aplicación de la ley en su literalidad, pese a su contradicción insalvable con derechos reconocidos nacional o internacionalmente, pueda efectuar alguna declaración que sirva para que se produzcan remedios legislativos futuros: tal sería, por ejemplo, lo previsto en el artículo 4 de la Human Rights Act británica, que regula la formulación de declarations of incompatibility por parte del tribunal que deba aplicar una norma contraria al contenido de los derechos del Convenio Europeo, incorporados al ordenamiento británico por esa ley. En forma más efectiva para la salvaguardia del derecho en cuestión, cabe, en muchos ordenamientos, que el juez suspenda el procedimiento en cuestión y plantee la cuestión de inconstitucionalidad al Tribunal Constitucional u órgano equivalente: valga señalar que en el caso español, la Ley Orgánica del Poder Judicial admire esta posibilidad "cuando por vía interpretativa no sea posible la acomodación de la norma al ordenamiento constitucional” ( art. 5.3) haciendo así preferente la "interpretación conforme”.

La solución más radical a la posible contradicción entre normas legales y derechos reconocidos a nivel constitucional o internacional consiste obviamente en la aplicación preferente de estos últimos, dejando sin efecto la norma legal, pese a su origen en la voluntad popular. En lo que se refiere a la contradicción entre normas legales y derechos constitucionales, el sistema de control difuso de la constitucionalidad, siguiendo un modelo similar al bien conocido de los Estados Unidos de América, ofrece un ejemplo de esa aplicación preferente, partiendo de la supremacía de la Constitución. En lo que se refiere a la eventual contradicción entre normas legales y derechos contenidos en convenio internacionales, la solución adoptada en algunos casos ha sido la considerar que los tratados internacionales (y entre ellos los convenios internacionales de derechos humanos) son de aplicación preferente respecto de las normas legales, y puede el juez ordinario adoptar su decisión al respecto a la vista de la jerarquía de las fuentes; tal sería por ejemplo, dentro del sistema regional europeo, la posición adoptada por el Consejo Constitucional francés, a partir de conocida resolución 
en el caso Interruption volontaire de grossesse (15 de enero de 1975)25. Por lo que atañe al contexto regional inter-americano, como es bien sabido, la Corte de San José ha venido a establecer, en Sentencias como la del caso Almonacid Arellano contra. Chile el denominado control de convencionalidad26,y, aún más, un control de convencionalidad difuso por parte de las autoridades (sobre todo judiciales) de los Estados.

Por lo que se refiere a las autoridades judiciales, la fuerza vinculante de la Convención (en la forma en que la Corte la interprete) les obliga, (dentro de las formas establecidas en sus ordenamientos) a la inaplicación de las normas internas que se opongan a aquéllas27. Valga señalar que el Tribunal Europeo no ha adoptado esta posición. Ha preferido centrarse en la declaración, en las circunstancias del caso concreto, de la eventual violación de algún derecho del Convenio, contentándose en ocasiones, con criticar la falta de protección interna del mismo.

\section{IX.- BIBLIOGRAFÍA}

ANDRÉS IBAÑEZ, P., "La independencia judicial y los derechos del juez”, en SAIZ ARNAIZ, A. (Dir.), Los derechos fundamentales de los jueces, Marcial Pons, Madrid, 2012.

BASTIDA FREIJEDO, F, et. al. Teoría General de los Derechos Fundamentales en la Constitución española de 1978, Tecnos, Madrid, 2004.

BURGOGUE LARSEN, L. y MONTOYA CÉSPEDES, N., "El diálogo judicial entre el TEDH y la CIDH” en LÓPEZ GUERRA, L. y SAIZ ARNAIZ, A. (Dirs.), Los sistemas interamericano y europeo de protección de los derechos humanos, Palestra, Lima, 2015.

CANOSA USERA, R., El control de convencionalidad, Aranzadi, Cizur Menor, 2015.

ESCOBAR, G., Introducción a la teoría jurídica de los derechos humanos, Universidad de Alcalá, Madrid, 2004.

FERRAJOLI, L., Derecho y razón. Teoría del garantismo penal, Trotta, Madrid, 2009.

LÓPEZ GUERRA, L., “Constitutionality, Conventionality and National Courts” en New Developments in Constitutional Law.

\footnotetext{
${ }^{25}$ Sobre esta cuestión, LÓPEZ GUERRA, L., “Constitutionality, Conventionality and National Courts” en New Developments in Constitutional Law, cit. (nota 1) pp. 259-270, 263.

${ }^{26}$ Ver sobre esta cuestión, CANOSA USERA, R., El control de convencionalidad, Aranzadi, Cizur Menor, 2015.

27 Una amplia exposición sobre las consecuencias del control de convencionalidad puede encontrarse en GARCÍA RAMÍREZ, S., "El control judicial interno de convencionalidad” en SAIZ ARNAIZ, A. y FERRER MAC GREGOR, E., Control de convencionalidad, interpretación y dialogo judicial. Una visión desde América Latina y Europa, Porrúa, México, 2012, pp. 269-306.

Revista de Estudios Jurídicos nº 18/2018 (Segunda Época) ISNN-e 2340-5066. Universidad de Jaén (España)

Versión electrónica: rej.ujaen.es
} 
LÓPEZ GUERRA, L., El Poder Judicial en el Estado Constitucional, Lima, Palestra, 2001.

LÓPEZ GUERRA, L., "La evolución de los sistemas de protección internacional de los derechos humanos”, en Parlamento y Constitución. Anuario, 18, 2017.

LÓPEZ GUERRA, L., "El Tribunal Constitucional y el principio stare decisis”, en El Tribunal Constitucional (Vol. II), Instituto de Estudios Fiscales, Madrid, 1981.

MATSCHER, F., "Les contraints de l'interprétation juridictionnelle”. Les méthodes d'interprétation de la Convention Européenne en SUDRE, F., (Ed.), L'interprétation de la Convention européenne des droits de l’homme, Bruylant, Bruselas, 1998.

MONTESQUIEU, El espíritu de las leyes, Libro XI, Capítulo VI, “De la constitución de Inglaterra”.

MURILLO DE LA CUEVA, P., "La independencia judicial y la ley” en BANDRES SÁNCHEZ CRUZAT J., y CONTRERAS CASADO, M. (Dirs.) Parlamento y Poder Judicial, Consejo General del Poder Judicial, Madrid, 2007.

ORTEGA GARCÍA, R., (Coord.) Interpretación y argumentación jurídica en el Estado Constitucional, Tirant lo Blanch, México, 2015.

PÉREZ TREMPS, P., "Los derechos fundamentales. Teoría general” en PEREZ TREMPS, P., (Coord.) Los derechos fundamentales, Corporación Editora Nacional, Quito, 2004.

REVENGA SÁNCHEZ, M., Derechos Fundamentales y constitucionalismo, Editorial Porrúa, México, 2014.

SAIZ ARNAIZ, A., "Capítulo 9: la interpretación de conformidad y su dimensión práctica” en LÓPEZ GUERRA, L. y SAIZ ARNAIZ, A. (Dirs.), Los sistemas interamericano y europeo de protección de los derechos humanos. Una introducción desde le perspectiva del diálogo entre tribunales. Lima, Palestra, 2015.

WOJTYCZEK, K., "International and European Standards of State Organization” en MOTOC, I. et. al (Eds.), New Developments in Constitutional Law. Essays in Honour of Andras Sajo, Eleven International Publishing, The Hague, 2018.

ZAGREBELSKY, G. El Derecho dúctil, Trotta, Madrid, 1995. 